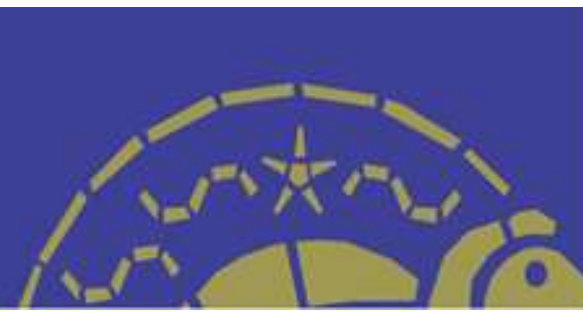

\title{
FOGÃO SOLAR: FERRAMENTA VIÁVEL PARA COZIMENTO DE ALIMENTOS A PARTIR DE MATERIAIS DE BAIXO CUSTO
}

\author{
Camila Vitorino dos Santos \\ Faculdade de Tecnologia de Jundiaí \\ Camilavitorino85@gmail.com \\ Tânia Rita Gritti Ferraretto \\ Faculdade de Tecnologia de Jundiaí \\ prof.tania@fatecjd.edu.br
}

\begin{abstract}
Resumo
$\mathrm{Na}$ busca do desenvolvimento de projetos voltados à utilização de energia limpa e renovável, a energia solar vem ganhando destaque nos últimos anos. Esta configura-se como uma fonte de energia abundante e inesgotável, uma vez que é proveniente de fenômenos naturais e possibilita a captação e conversão em outras formas de energia. Estudos relatam a importância e viabilidade da utilização de muitos equipamentos, dentre estes, o fogão solar para cocção de vários alimentos. Deste modo, o presente estudo objetivou apresentar uma ferramenta viável e barata para fins de cozimento de alimentos e fervura (desinfecção) da água, a construção de um fogão solar tipo caixa, contribuindo com as futuras operações do Projeto Rondon, as quais têm lugar em regiões com forte incidência de luz solar, norte e nordeste do Brasil. Durante o evento I Jornada de Pesquisa, Extensão e Cultura- I Mostra de Projetos, realizado nos dias 4 a 8 de maio de 2015 na Faculdade de Tecnologia de Jundiaí (FATEC- JD), pode-se compreender o princípio de funcionamento de um fogão solar construído pelos alunos do Curso de Tecnologia em Gestão Ambiental (GAM), sendo possível identificar sua eficiência e bom desempenho ao realizar o cozimento de alimentos. A partir da Mostra de Projetos pensou-se na viabilidade do seu uso em comunidades carentes, principalmente, as que utilizam fogão a lenha, e em regiões com grande potencial solar, caso do Nordeste, podendo ser substituído, parcialmente, para o cozimento de determinados alimentos como arroz, macarrão, além da fervura da água.
\end{abstract}

Palavras-chave: Fogão solar. Energia solar. Meio ambiente. Materiais recicláveis.

\section{SOLAR STOVE: A VIABLE TOOL FOR COOKING FOOD USING LOW COST MATERIALS}

\begin{abstract}
Due to the pursuit of project development focused on the use of clean and renewable energy, solar energy has been gaining momentum in recent years. Because it derives from natural phenomena, the solar energy is a source of abundant and limitless energy and allows the capture and conversion to other energy forms. Literature reports the importance and feasibility of using diverse equipment, including solar stove, for cooking of various food. Therefore, the objectives of the present study were to display a low cost and viable tool for food cooking purposes and boil (disinfection) of water, and to build a box type solar stove, which in turn may contribute with future actions of Projeto Rondon, which occur in regions of ample daylight incidence, North and Northeast of Brazil. During the I Jornada de Pesquisa, Extensão e Cultura- I Mostra de Projetos, realized from 4 to 8 of May, 2015 at Faculdade de Tecnologia de Jundiaí (FATEC- JD), it was possible to understand the working principle of a solar stoven built by students of Curso de Tecnologia em Gestão Ambiental (GAM), and to identify the performance and efficiency for cooking food with this tool. After the Mostra de Projetos it was discussed the viability of solar stove use in underprivileged communities, particularly those that use wood burning stove or in regions with high solar potential, such as Northeast, possibly through the partial replacement of stove to cook particular ingredients such as rice, pasta and boiling water.
\end{abstract}

Key words: Solar stove. Solar energy. Environment. Recycling. 


\section{SOLAR STOVE: A VIABLE TOOL FOR COOKING FOOD USING LOW COST}

\section{MATERIALS}

\section{Resumen}

En busca del desarrollo de proyectos dirigidos al uso de Energía Limpia y Renovable impulso, la energía solar Una ha ido ganando en los últimos años. Configuración como una energía abundante e inagotable, ya que se trata de fenómenos naturales y permite la captura y conversión de las Naciones Unidas a otras formas de energía. Los estudios informan importancia y factibilidad de uso de muchos dispositivos, entre ellos, la cocina solar para cocinar seleccionado de los Alimentos. En este modo, el presente estudio tuvo como objetivo presentar una herramienta viable Correo de bajo costo para las aletas de preparar la comida y hervir (desinfección) de agua, la construcción de un cuadro de tipo solar, estufa, contribuyendo como futuro funcionamiento Proyecto Rondón, como la OMS tiene lugar en regiones con fuerte incidencia punto de luz del sol, norte y noreste de Brasil. Durante el evento I Jornada de Investigación, Extensión y Cultura-I muestran proyectos en día lugar del 4 al 8 de mayo de a la de 2015, de la Facultad de Tecnología de Jundiaí (FATEC- JD), uno puede entender el principio de funcionamiento de un cocina solar construido por los estudiantes del Curso de Tecnología en Gestión Ambiental (GAM), que puede identificar su eficiencia y buen desempeño al realizar la cocción de alimentos. De la serie de proyectos se pensó Hacer la viabilidad de su uso en las comunidades marginadas, especialmente a los usados por estufa de leña de la ONU, y en regiones con alto potencial solar, caso del Nordeste, sustituida puede ser parcialmente a la cocción de cierta Puesto que el arroz comida, pasta, además de la de ebullición del agua.

Palavras clave: Estufa solar. Energía solar. Ambiente. Reciclaje 
Fogão solar: ferramenta viável para cozimento de alimentos a partir de materiais de baixo custo

\section{INTRODUÇÃO}

Atualmente nota-se o crescente interesse em projetos voltados para o aproveitamento de fontes de energia renováveis, em substituição aos combustíveis fósseis. Caracterizam-se como fontes de energia não renováveis, aquelas cujas reservas diminuem com o seu uso e sua reposição na natureza pode levar milhões de anos, como é caso do petróleo. Já as fontes de energia renováveis, são aquelas que podem ser repostas pela natureza em períodos curtos de tempo, uma vez que são provenientes de fenômenos naturais oriundos da conversão da radiação solar. Entre as fontes renováveis, incluem-se a energia hídrica, eólica, de biomassa e a solar (SILVA et. al., 2009; MACEDO NETO et. al., 2011).

Sabendo-se que a maior parte da energia utilizada na Terra é proveniente do Sol e que é por meio dele que se originam praticamente todas as outras fontes de energia, o aproveitamento da energia solar é atualmente uma das alternativas mais viáveis para o desenvolvimento de sistemas de captação e conversão em outras formas de energia, principalmente por ser abundante e inesgotável, tanto como fonte de calor como de luz (MACEDO NETO et. al., 2011; RAMOS FILHO, 2011).

Segundo MACEDO NETO et. al., 2011, de toda a radiação solar que incide na nossa atmosfera, somente $25 \%$ chega ao solo de forma direta, pois ao longo da atmosfera a radiação solar sofre reflexões, absorções e dispersões. Sendo assim, a radiação global que é coletada em solo, é resultante da radiação direta, difusa e refletida.

Nesse contexto, considera-se o Brasil um país privilegiado em decorrência de sua posição geográfica apresentando grande potencial energético, devido à grande incidência de radiação solar, sendo, portanto, bastante favorável ao uso de equipamentos solares. O Brasil possui significativo potencial solar com disponibilidade equivalente a $1,13 \times 10^{10} \mathrm{GWh}$, em quase todo o ano, como acontece no Nordeste (MACEDO NETO et. al., 2011; SILVA et. al., 2009).

Entre os equipamentos que podem ser construídos visando à utilização por meio da energia solar, existem os coletores planos, os secadores solares (de frutas e grãos), as placas fotovoltaicas e os fogões solares objeto desse estudo.

Os fogões solares são dispositivos especiais que, por intervenção da luz solar é possível gerar calor para cozinhar alimentos, aquecimento de água e outras finalidades (RAMOS FILHO, 2011).

Sabe-se que desde a antiguidade muitos povos utilizavam a energia do sol para aquecer água, secar frutas e cozer vegetais. A primeira cozinha solar com tecnologia moderna se atribui ao franco-suíço Horace de Suassure no ano de 1767, que construiu um fogão solar onde cozinhou 
Fogão solar: ferramenta viável para cozimento de alimentos a partir de materiais de baixo custo

frutas. Este sistema era composto por duas caixas de madeira de pinho, uma dentro da outra, isoladas com lã e tinha três coberturas de vidro que alcançava temperaturas de $190^{\circ} \mathrm{F}-88^{\circ} \mathrm{C}-$ (MACEDO NETO et. al., 2011; SOLAR COOKING, 2015).

Posteriormente, começaram a surgir outros fogões solares, os quais tiveram maior difusão por volta dos anos 80, com a popularização do Solar Chef de Sam Erwin, tornando-se o mais eficiente forno solar doméstico. Além disso, diante do panorama do aquecimento global e com a Primeira Conferência Mundial sobre Cozinha Solar em 1992, que foi realizada pela associação Solar Cookers Internacional reunindo pesquisadores de dezoito países, visando à construção e o uso de fogões solares por meio de organizações filantrópicas, deu-se a expansão da utilização dos fogões solares pelo mundo. O último evento ocorreu ano de 2006, na Espanha (RAMOS FILHO, 2011; SOLAR COOKING, 2015).

No Peru foi desenvolvido um programa de construção de fogões solares a cargo da organização filantrópica Peru Children's Trust, que através da mão de obra de cem crianças pobres oferece às famílias saúde e educação. Já no Quênia, a Solar Cookers Internacional financiou um programa que permitiu a compra de fogões solares para mais de 15 mil famílias que vivem em campos de refugiado (RAMOS FILHO, 2011).

No Brasil, o estudo de fogões solares teve início na década de 80. O Laboratório de Energia Solar da Universidade Federal da Paraíba (UFPB) foi pioneiro nesse estudo, construindo vários tipos de fogões solares e utilizando diferentes materiais. Atualmente a Universidade Federal do Rio Grande do Norte (UFRN), através do Laboratório de Energia Solar e Máquinas Hidráulicas é a promissora nessa linha de pesquisa, construindo diversos fogões solares concentradores e do tipo caixa, somando mais de 20 anos de estudos (RAMOS FILHO, 2011; SOUZA et. al., 2010).

Na I Jornada de Pesquisa, Extensão e Cultura- I Mostra de Projetos, realizado entre os dias 4 e 8 de maio de 2015 na Faculdade de Tecnologia de Jundiaí (FATEC- JD), pode-se compreender o princípio de funcionamento de um fogão solar, o qual foi construído pelos alunos do $1^{\circ}$ semestre do Curso de Tecnologia em Gestão Ambiental do ano de 2014 sob a orientação da Prof ${ }^{a}$ Eng. Tânia Rita Gritti Ferraretto.

Sendo assim, no presente trabalho propõe-se a construção de um fogão tipo caixa utilizando-se material de baixo custo, com o objetivo de contribuir com as futuras operações do Projeto Rondon, apresentando-o como uma ferramenta viável e barata para fins de cozimento de alimentos e fervura (desinfecção) da água.

Uma vez que o Projeto Rondon realiza-se em municípios com grande insolação como, por exemplo, aqueles localizados na região nordeste do país, e, sabendo-se que 30\% da madeira 
Fogão solar: ferramenta viável para cozimento de alimentos a partir de materiais de baixo custo

retirada da caatinga do nordeste transforma-se em lenha para cozimento de alimentos, justifica-se a importância do uso do fogão solar nessas regiões pela facilidade do aproveitamento energético e pela redução de alguns impactos ambientais, como desmatamento, emissões de $\mathrm{CO}_{2}$, perigo de incêndio e explosão, melhoria de saneamento e esforço físico da população em busca da lenha. Além disso, a utilização do fogão tipo caixa representa uma alternativa viável e econômica para a população, pois o material utilizado para a confecção é de baixo custo.

\section{MATERIAIS E MÉTODOS}

O fogão solar tipo caixa é, usualmente, construído a partir de materiais de baixo custo, neste caso especifico, por materiais recicláveis. Sua estrutura é composta por duas caixas de papelão, uma dentro da outra. Sua tampa, bem como suas paredes, é revestida com material refletivo e reciclável: as caixas de leite tetra pak. Esse material, a embalagem tetra pak, possibilita a passagem dos raios solares para o interior da caixa, concentrando boa parte do calor e promovendo o cozimento do alimento. Objetivando-se uma maior absorção de calor, pode-se pintar o fundo da caixa menor de preto ou colocar ali uma chapa de metal. Este tipo de fogão solar pode ser montado e desmontado de forma muito fácil, simples e barata. Também simples é a sua utilização: uma vez montado coloca-se a panela no centro da caixa onde esta recebe diretamente a radiação solar favorecendo o cozimento do alimento (figura 1).

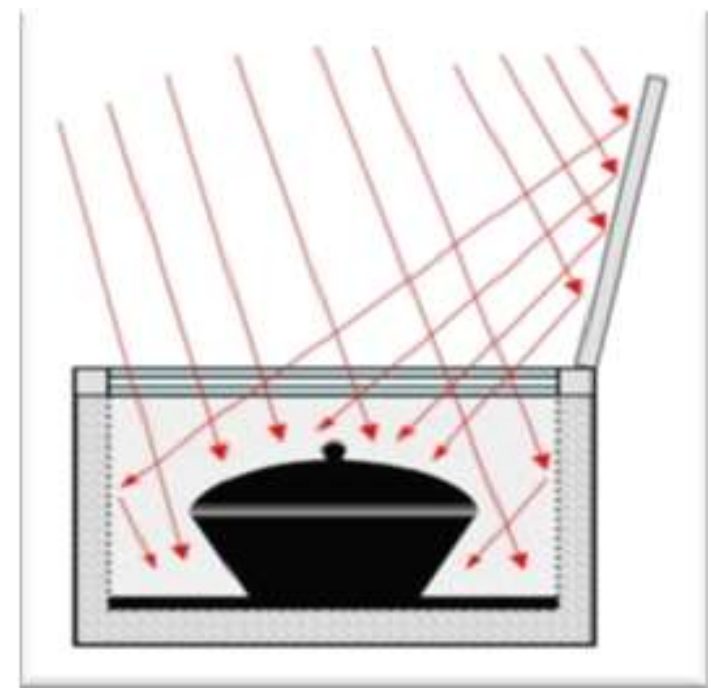

Figura 1- Modelo de Fogão Solar tipo Caixa. Fonte: Sociedade Solar, 2015.

Esse tipo de fogão solar é muito viável em comunidades carentes principalmente as que utilizam fogão a lenha, podendo ser substituído parcialmente para o cozimento de determinados 
Fogão solar: ferramenta viável para cozimento de alimentos a partir de materiais de baixo custo

alimentos como arroz, macarrão, batata, entre outros, além da fervura da água (RAMOS, 2011). Além disso, seu princípio de funcionamento consiste em uma caixa térmica receptora e concentradora de raios solares, constituindo-se numa estufa.

\section{RESULTADOS E ANÁLISE}

Com base no evento realizado na I Jornada de Pesquisa, Extensão e Cultura- I Mostra de Projetos, realizado em entre os dias 4 e 8 de maio de 2015 na Faculdade de Tecnologia de Jundiaí (FATEC- JD), pode-se perceber que o fogão solar construído com materiais recicláveis pode ser muito útil em atividades simples do cotidiano, como o cozimento de alimentos e a fervura de água (desinfecção).

Durante a realização do Projeto Rondon no período de 18 de janeiro a 01 de fevereiro de 2015 no município de Arari - MA, observou-se a grande incidência da luz solar na região nordeste do país, principalmente na zona rural, fato este, identificado nos municípios de Aranha e Arari-Açú/MA. Ressalta-se ainda que muitas famílias não possuem o fogão convencional, a gás, utilizando-se da lenha para cozimento.

Esta situação piora cada vez mais a condição de vida da população, pois acarreta problemas de saúde em decorrência do aumento da poluição interna em suas residências, doenças respiratórias e pulmonares, cansaço físico, desidratação, aumento das emissões de $\mathrm{CO}_{2}$, desmatamento, entre outros. Por esse motivo, o fogão solar apresenta-se como uma forma viável para a cocção de alimentos, principalmente para as comunidades carentes, pois apresenta resultados favoráveis como facilidade de uso e confecção, podendo ser utilizado para cozinhar e assar alimentos simples (bolos, pães, macarrão, arroz, fervura de água), construído com materiais de baixo custo e melhorando o bem estar de quem o utiliza.

Além disso, destaca-se que a incorporação desta tecnologia é sustentável, pois contribui de forma satisfatória com os aspectos econômicos, sociais e ambientais, uma vez que utiliza fonte renovável, abundante e inesgotável, se comparado com o fogão à lenha, o qual é utilizado pela população de maior vulnerabilidade social, a qual vive em situação de risco e com maior pobreza.

Entretanto, destaca-se que o fogão solar não substitui o fogão convencional, pois este depende do clima e deve ser utilizado fora de casa para seu funcionamento, não podendo ser utilizado em dias chuvosos ou à noite, tornando-se uma ferramenta alternativa. Além disso, cada alimento tem seu tempo de cozimento. 
Fogão solar: ferramenta viável para cozimento de alimentos a partir de materiais de baixo custo

Deste modo, evidencia-se a importância da construção do fogão solar nas futuras atividades do Projeto Rondon, uma vez que propicia a melhora das condições de vida da população, com a diminuição de problemas de saúde pública, de degradação ambiental e benefícios econômicos na renda familiar.

\section{CONSIDERAÇÕES FINAIS}

O fogão solar proposto mostrou-se uma opção viável para ser utilizado nos processos de cozimento e fervura de água, além de ser um forte contribuinte para a conservação do meio ambiente, principalmente quanto ao desmatamento por uso de lenha.

Considerando que sua operação é simples, em função do material utilizado para sua construção, os materiais recicláveis (caixas de papelão, caixas de tetra pak) e seus processos (montagem e desmontagem), podem ser facilmente fornecidos às comunidades carentes, favorecendo a melhoria em suas condições de vida. Este conhecimento pode ser expandido pelas atividades desenvolvidas no Projeto Rondon, mostrando a essas comunidades uma alternativa viável, em função do seu custo benefício e, principalmente, por usar um combustível inesgotável e abundante em sua região, além da preservação do meio ambiente podendo propiciar uma economia na renda familiar.

\section{REFERÊNCIAS}

MACEDO NETO, M. C; GOMES, Í. R. B; GONDiM, P. C. A; SOUZA, L. G. M. Desenvolvimento de um fogão solar com parábola fabricada em material compósito a base de isopor e gesso. Revista Holos, Natal, v. 5, n. 27, p. 117-135, dez. 2011.

RAMOS FILHO, R. E. B. Análise de Desempenho de um Fogão Solar Construído a Partir de Sucatas de Antena de TV. Dissertação (Mestrado em Engenharia Mecânica) Programa de Pós Graduação em Engenharia Mecânica. Universidade Federal do Rio Grande do Norte, Natal, 2011. $94 \mathrm{f}$.

SILVA, L. L; ALVES, M. S; SILVA, V. C; ROCHA, A. L. Princípios de termoelétricas em pequenas propriedades rurais. In: INTERNATIONAL WORKSHOP ADVANCES IN CLEANER PRODUCTION, 2, 2009, São Paulo. Anais... São Paulo: IFECTA, 2009. p. 1-9. 
Fogão solar: ferramenta viável para cozimento de alimentos a partir de materiais de baixo custo

SOCIEDADE SOLAR. Manual online do Forno Solar de baixo custo: Projeto experimental do Forno solar feito com embalagens Tetra park. 2015. Disponível em: http://www.sempresustentavel.com.br/solar/czsolar/forno-solar.htm. Acesso em: 20 jun. 2015. SOLAR COOKING. Uma História de cozimento solar. Artigo extraído do livro de Joe Radabaug, Heaven's Flame. 2015. Disponível em: http://solarcooking.org/portugues/historypt.htm. Acesso em 13 jun. 2015.

SOUZA, L. G. M; RAMOS FILHO, R. E. B; JÚNIOR, A. P. M. VI Congresso Nacional de Engenharia Mecânica- VI CONEM 2010. 2010. Campina Grande- Paraíba. Fogão solar com parábola reciclável de antena. Associação Brasileira de Engenharia e Ciências Mecânicas. Editora da UFCG. v. 1, p 1-9. 